\title{
OTORGAMIENTO DE FUNCIONES JURISDICCIONALES A LAS AUTORIDADES ADMINISTRATIVAS EN COLOMBIA: ¿EMPODERAMIENTO AL EJECUTIVO?
}

\author{
Granting Jurisdictional Functions to Administrative Authorities in Colombia: Empowering the
} Executive?

\author{
MARÍA LOURDES RAMÍREZ TORRADO* \\ Universidad del Norte
}

NELSON HERNÁNDEZ MEZA*

Universidad del Norte

\section{RESUMEN}

Este artículo analiza el ejercicio de las funciones jurisdiccionales por parte de las autoridades administrativas, en Colombia, luego de la promulgación de la constitución de 1991. Debido a que ni la doctrina científica, como tampoco la ley, la jurisprudencia y los documentos institucionales entregan una justificación al otorgamiento de funciones a las autoridades administrativas. Planteándose el interrogante si el empoderamiento de las autoridades administrativas responde a un modelo articulado de justicia que garantiza los derechos ciudadanos, o si es resultado de una política de empoderamiento del Poder Ejecutivo.

\section{PALABRAS CLAVE}

Administración, justicia, Estado, jurisdicción

\section{ABSTRACT}

The Law, the judgments and scientific research in the matter have not provided justifications for the jurisdictional functions of administrative authorities. Hence, this article analyzes the exercise of jurisdictional functions by administrative authorities in Colombia, after the enactment of the 1991 constitution. For doing this, we have studied if the empowerment of the administrative authorities responds to an articulated model of justice, or if it is the result of a policy of empowerment of the Executive Power.

\section{KEYWORDS}

Administration, Justice, State, Jurisdictional

\section{Introducción}

Desde la constitución de 1991, la oferta en administración de justicia, en Colombia, se ha ampliado, pues a la par del poder judicial se ha venido empoderando al Ejecutivo con esta función, en distintos sectores caso de: consumo, competencia, propiedad industrial, derechos de autor, salud, entre otros. A priori, esta oferta presenta ventajas, como es el acceso al servicio a partir del uso de tecnologías, la especialidad del juez, la disminución en los tiempos de decisión; sin embargo otras tantas cuestiones plantean interrogantes como lo son: igualdad en acceso a la justicia, uso de tecnologías, los recursos, la autonomía e independencia del juzgador,

\footnotetext{
* Doctora en derecho administrativo, Universidad Carlos III (Madrid). Magíster en derechos fundamentales, Universidad de Lovaina (Lovaina). Abogada, Universidad del Norte (Barranquilla, Colombia). Profesora investigadora de la División de Derecho, Ciencia Política y Relaciones Internacionales de la Universidad del Norte (Barranquilla, Colombia). Correo electrónico: torradom@uninorte.edu.co, orcid.org/0000-0001-6529-0457.

** Estudiante del Doctorado en Derecho y Becario de la Universidad del Norte. Magíster en Derecho, Universidad del Norte, Abogado, Universidad del Norte (Barranquilla, Colombia). Correo electrónico: nelsonh@uninorte.edu.co.
} 
entre otros temas. Preguntas que tendrían respuesta si existiera una política, con aportes de todos los sectores, que regulara de forma sistémica esta incursión del ejecutivo en un tema que en principio le es ajeno.

Así las cosas, el objetivo de esta investigación, es conocer cuáles han sido los escenarios y motivaciones que han rodeado al otorgamiento paulatino y creciente de las funciones jurisdiccionales al poder ejecutivo; $y$ asimismo identificar los diferentes argumentos entregados, los últimos 28 años, por los distintos actores (poder judicial, gobierno, Corte Constitucional, Consejo de Estado y doctrina) para justificar este modelo de justicia. Y con ello, se podrá definir si es consecuencia de una política conjunta, para aumentar la oferta de justicia a la comunidad y dar respuesta a ciertos sectores de la sociedad para solucionar las controversias, o una manera de fortalecer al poder ejecutivo.

Para lograr este objetivo se acudió a la investigación documental, revisando y analizado una a una las leyes, los decretos del Ejecutivo, los Acuerdos del Consejo Superior de la Judicatura, los planes sectoriales de desarrollo del Poder Judicial, así como las decisiones judiciales, de la Corte Constitucional y del Consejo de Estado en el tema objeto de estudio, los últimos 28 años. Toda esta información fue analizada, en tres etapas, marcadas cada una de ellas por las novedades legislativas en materia de reforma a la justicia en el país. Precedido ello, por el planteamiento del escenario de estas entidades. Hallándose que los silencios de los distintos actores han permitido que al ejecutivo, con disimiles argumentos, se le haya empoderado paulatinamente de la nada despreciable función de dirimir controversias en una sociedad.

\section{Escenario de las entidades que cumplen funciones jurisdiccionales}

A día de hoy son casi una decena de entidades del poder ejecutivo que administran justicia en el país; cumpliendo dicha función la mayoría luego que entrara en vigencia la constitución del 91 (Superintendencia Financiera, Superintendencia de Industria y Comercio; y la Superintendencia Nacional de Salud, el ICA — Instituto Colombiano Agropecuario-, y la Dirección Nacional de Derechos de Autor), sin olvidar las que ya venían cumpliendo la actividad antes de adoptarse la Carta Superior hoy vigente, verbigracia: comisarios de familia, defensores de familia, la Superintendencia de Sociedades, o la Dirección Marítima.

El fundamento constitucional de esta actividad es el artículo 116, cuyo objetivo, quizás pues no quedo claro en los debates de la constituyente, fue responder a las nuevas realidades de la actividad de la administración, descongestionar los despachos judiciales o emular a las autoridades regulatorias en boga ${ }^{1}$, para la época, en los países anglosajones y la Unión Europea. Al contrario sí está claro a día de hoy, según doctrina de la Corte Constitucional, es el hecho que el legislador es quien debe otorgar dicha función, de manera excepcional, justificándose por razones eminentemente de especialidad.

Son varias y disimiles las materias y las entidades del poder ejecutivo a las que se les han atribuido funciones jurisdiccionales. Algunas de las materias cuyas controversias son dirimidas por estas autoridades son las relativas con: competencia, consumo, financiero, societario, salud, patentes, propiedad industrial, infancia, derechos de autor o asuntos marítimos.

Han sido, igualmente, distintos los diseños institucionales ${ }^{2}$ que se han empleado para que la administración realice esta actividad, siendo la más recurrente las superintendencias, pero también los establecimientos públicos o las unidades administrativas especiales.

En el caso de la Superintendencia de Sociedades tenemos que esta realiza funciones jurisdiccionales en temas societarios, en diversos asuntos, a través de dos delegaturas: una, la de procedimientos mercantiles que actúa a través de grupos de trabajo ${ }^{3}$. $Y$ otra, la delegatura

\footnotetext{
1 PINILLA (2008), p. 365.

2 SANTELICES (2012), p. 240.

${ }^{3}$ Por ejemplo, los grupos de jurisdicción societaria I y II. Conocen de toda clase de conflictos de naturaleza societaria: a) acciones sobre abuso del derecho de voto; b) acciones sobre responsabilidad de los administradores; c) resolución de conflictos societ arios;
} 
para procedimientos de insolvencia ${ }^{4}$, dividida en grupos de trabajo ${ }^{5}$. Por su parte la Superintendencia de Industria y Comercio tiene competencia en materia de derecho del consumidor, propiedad industrial y competencia desleal, atendiendo la gestión de estos asuntos a través de grupos de trabajos de trabajo ${ }^{6}$ que se dividen la atención de estos asuntos en cada materia. Mientras que la Superintendencia Financiera de Colombia actúa en asuntos puntuales, de naturaleza financiera, seguros y comerciales, a través de una delegatura para asuntos jurisdiccionales ${ }^{7}$. Por su parte la Superintendencia Nacional actúa en temas de salud, y en asuntos relacionados con salud de carácter económico ${ }^{8}$, a través de una delegatura para asuntos jurisdiccionales. Y cuenta con un procedimiento de conciliación previo, que no existe en otra superintendencia.

La actividad jurisdiccional realizada por las superintendencias se concentra en la ciudad de Bogotá, a pesar que estas entidades cuentan con oficinas desconcentradas en distintas ciudades con la finalidad de acercar el servicio a la comunidad. Ejemplo de ello es la Superintendencia de Sociedades que tiene cobertura en ocho (8) ciudades de Colombia ${ }^{9}$, o al Superintendencia de Industria y comercio con sede en diecisiete (17) ciudades $^{10}$ o la Superintendencia Nacional de Salud ${ }^{11}$.

Ahora, existen otras autoridades del orden nacional como la DIMAR-Dirección General Marítima $-{ }^{12}$ que tiene funciones jurisdiccionales en temas específicos que tienen que ver como asuntos marítimos, que actúa con procedimientos ajustados a la constitución ${ }^{13}$, pero que tienen particularidades frente al proceso judicial. El ICA ${ }^{14}$ que tiene funciones jurisdiccionales en materia de propiedad intelectual pero solo en cuanto a violación de derechos de obtentor de variedades vegetales. $Y$ otras de este orden, pero que tienen la particularidad que las funciones no están radicadas en la entidad sino en los funcionarios de esta, como es el caso del ICBF Instituto Colombiano de Bienestar Familiar $-{ }^{15}$ y de sus defensores de familia, que tienen asignadas funciones en asuntos de familia y niñas, niños y adolescentes. Así como otras que tienen la categoría de unidad administrativa especial como la Dirección de Derechos de Autor ${ }^{16}$

d) acciones sobre desestimación de la personalidad jurídica; e) asuntos relacionados con la designación de peritos; e) discrepancias sobre el acaecimiento de causales de disolución; f) ejecución específica de acuerdos de accionistas; g) impugnación de decisiones sociales; h) reconocimiento de presupuestos de ineficacia; i) responsabilidad de socios y liquidadores; j) oposición a la reactivación empresarial.

${ }^{4}$ SUPERINTENDENCIA DE SOCIEDADES (2016), Art. 25.

${ }^{5}$ El grupo de reorganización; grupo de procesos especiales; grupo de liquidaciones; grupo de intervenidas; grupo de acuerdos de insolvencia en ejecución.

${ }^{6}$ SUPERINTENDENCIA DE INDUSTRIA Y COMERCIO (2017).

${ }^{7}$ Los asuntos en los cuales ejerce función jurisdiccional la SFC son: i) el reconocimiento de los presupuestos de ineficacia en los casos previstos en el libro segundo del código de comercio relativo a sociedades comerciales; ii) la solución de asuntos de naturaleza societaria relativos a la discrepancia sobre el precio de alícuotas respecto a sociedades vigiladas por la SFC en ciertos eventos; iii) la protección de accionistas minoritarios de sociedades que participen como emisores de valores en el mercado público de valores que se vean afectados por decisiones que tomen los órganos de administración de la sociedad; $y$, iv) diferencias entre consumidores financieros (personas naturales o jurídicas, que están en una etapa pre contractual, contractual, legal o que utilizan los servicios financieros de una entidad vigilada por la SFC) y estas entidades, en asuntos relacionados con la ejecución y cumplimiento de obligaciones contractuales realizadas con ocasión de la actividad financiera, bursátil y aseguradora. No obstante, en el estatuto del consumidor se estableció una particularidad como excepción a su actividad jurisdiccional, como es la prohibición de conocer de procesos laborales. Prohibición respecto de la cual existe un silencio en la doctrina.

8 TOVAR (2013), p. 255.

${ }^{9}$ Bogotá, Barranquilla, Medellín, Manizales, Bucaramanga, Cartagena, San Andrés y Cali.

10 Bogotá, Armenia, Barranquilla, Bucaramanga, Cartagena, Cali, Cúcuta, Ibagué, Manizales, Medellín, Montería, Neiva, Popayán, San Andrés, Villavicencio, Pasto y Sincelejo.

${ }^{11}$ La oficina principal de la Superintendencia Nacional de Salud se encuentra ubicada en Bogotá; no obstante, existen oficinas regionales en: Medellín, Barranquilla, Bucaramanga, Cali, Neiva y Quibdó.

12 Esta facultad jurisdiccional está relacionada exclusivamente con la resolución de asuntos relativos a la violación de las normas que regulan las actividades marítimas, según lo dispone el Decreto № 2324, de 1984.

${ }^{13}$ Corte Constitucional. C-212/1994.

${ }^{14}$ El Código General del Proceso en el artículo 24, numeral 3, literal c), asigna al Instituto Colombiano Agropecuario facultades jurisdiccionales para dirimir los asuntos relativos a infracciones a los derechos de obtentor de variedades vegetales.

15 La Ley № 1098, de 2006, consagra algunas facultades a los Defensores de Familia relativas a la protección y representación de los niños, niñas y adolescentes en el marco de las actuaciones jurisdiccionales que se surten respecto de sus derechos.

16 Ley 1564/2012, de julio 12, artículo 24. Literal b) numeral 3, "en los procesos relacionados con los derechos de autor y conexos". 
que tiene estas funciones en materia de propiedad intelectual, cuya actividad ha sido objeto de críticas $^{17}$.

Se destaca que una cosa que tienen en común estas entidades es que muchas cuestiones se encuentran supeditadas al sector en concreto al que enfrentemos, ello debido a que no existe una norma que englobe la regulación del ejercicio de esta actividad. Manifestación de lo anterior, es el caso del control judicial de las decisiones, la naturaleza de los cargos de quienes administran justicia, su forma de nombramiento, la práctica y la valoración de la prueba, la ejecución de las sentencias, y los auxiliares de la justicia, entre otras muchas cuestiones. Sumado a lo anterior, a que no existe un órgano, asimilable al Consejo Superior de la Judicatura que se ocupe de: administrar, coordinar, planear y reglamentar la actividad jurisdiccional realizada por las distintitas entidades administrativas.

Si comparamos esta forma de justicia a la impartida por el poder judicial tenemos que en temas de acceso a la administración de justicia, se permite la presentación de la demanda por medios virtuales, (por ejemplo: superintendencias); otra distinción se señala en la manera misma de la toma de decisiones pues mientras en el poder judicial es la decisión del juez de manera individual, en el supuesto de algunas superintendencias descansa, en ciertos eventos, sobre grupos de trabajo. Qué decir del principio de jerarquía propio de la administración y los principios de autonomía e independencia judicial inherentes al poder judicial. Sin olvidar los tiempos que tienen para fallar las autoridades administrativas versus lo márgenes del poder judicial $^{18}$.

Así las cosas, y a pesar de ser una actividad que cobra cada vez más y más relevancia al ampliar su abanico de oferta e impactar a un mayor número de ciudadanos ha recibido un tratamiento secundario en las diversas reformas y modificaciones legislativas, pues estas se han concentrado más en la cuestión de la congestión judicial focalizando sus esfuerzos en mayor presupuesto y aumento del número de juzgados ${ }^{19}$ que en analizar esta realidad. $Y$ en el caso de la agenda del gobierno tampoco ha estado como prioridad organizar su funcionamiento ${ }^{20}$ hasta ahora, pues aquél se ha ocupado de temas como la política criminal, carcelaria y penitenciaria, la forma de elección de los integrantes de las altas cortes, la eliminación del Consejo Superior de la Judicatura y la forma gobierno de la rama judicial.

\section{Empoderamiento de las autoridades del ejecutivo los últimos 28 años}

Para lograr desentrañar los objetivos que ha perseguido el estado para atribuir funciones al ejecutivo, se han revisado las motivaciones consignadas en las distintas normativas, que se han ocupado en materia de administración de justicia desde $1991^{21}$. Los cuatro momentos analizados son: 1) Asamblea Nacional Constituyente; 2 ) Desde la entrada en vigencia del texto constitucional en 1991 y hasta antes de la expedición de ley 446/1998; 3) Desde la expedición de la ley 446/1998 hasta antes de la expedición del Código General del Proceso (2012); y, 4) Desde la expedición del Código General del Proceso (2012) hasta el presente.

\section{Asamblea Constituyente: inclusión sin discusión}

No se sabe a ciencia cierta las motivaciones y finalidades de la consagración constitucional ${ }^{22}$ que permitieron que se incluyera funciones jurisdiccionales a las autoridades administrativas, ya que la figura pasó inadvertidamente sin generar gran polémica; tal vez, porque no era una innovación ${ }^{23}$. Citándose como ejemplos los defensores de familia, inspectores

\footnotetext{
17 SALAS (2018), p. 349.

18 RAMÍREZ y HERNÁNDEZ (2018), p. 341.

19 TORRES (2015), p. 148.

${ }^{20}$ GARCÍA (2012), p. 29.

${ }^{21}$ Otra forma de estudiar el tema sería a partir de la construcción jurisprudencial elaborada por la Corte Constitucional.

22 BEJARANO (2018), p. 26.

${ }^{23}$ DURÁN y MALAGÓN (2016), p. 103.
} 
de policía y, la posibilidad que para entonces existía de la captura administrativa ${ }^{24}$, precisando que estos últimos en la actualidad no cuentan con dichas facultades.

Fueron solo en un par de intervenciones, del entonces Ministro de Justicia Jaime Giraldo Ángel, cuando se hizo mención a que la atribución de funciones jurisdiccionales a autoridades administrativas era algo que ya venía en nuestra legislación ${ }^{25}$. En los debates constituyentes ${ }^{26}$, una de las explicaciones que se dio fue que esta forma de justicia facilita resolver en un tiempo más rápido las controversias, sin perder la independencia propia de los jueces ${ }^{27}$.

De manera que no se esgrimieron por los constituyentes, de manera explícita, argumentos como: descongestión judicial, mora judicial, mecanismos alternativos de solución de conflictos, o factores económicos y del mercado, a fin de justificar su inclusión en el texto constitucional.

\section{Primer estadio: 1991-1998. Preocupación por justificar el empoderamiento al ejecutivo}

A diferencia de lo ocurrido en los debates constitucionales, se destaca de este periodo que los poderes ejecutivo y legislativo sí entregan distintos argumentos con miras a empoderar a distintas autoridades administrativas de las funciones jurisdiccionales. Estas motivaciones orbitan en la necesidad de descongestionar el poder judicial, la desjudicialización y la alternatividad en las formas de solución de controversias, siendo notorio el silencio del poder judicial, tanto en sus órganos administrativos como decisorios.

Este periodo arranca con los decretos del presidente de la república y termina con la primera ley estatutaria de la administración de justicia. Así las cosas, el presidente de la época, a través de funciones extraordinarias (decreto 2651 de 1991) ${ }^{28}$, otorga funciones jurisdiccionales a la Superintendencia de Sociedades ${ }^{29}$, enmarcándose dentro del programa de modernización de la administración de justicia, como mecanismo para la descongestión judicial ${ }^{30}$. Ello auspiciada por la USAID - Agencia de Estados Unidos para el Desarrollo Internacional-.

En lo que corresponde al Plan Sectorial de Justicia, para el periodo 1994-1998, no contempló ninguna alusión a las funciones jurisdiccionales de autoridades administrativas, no obstante, en un texto elaborado por el Ministerio de Justicia y del Derecho, sí expresa, que la atribución de funciones jurisdiccionales corresponde al fenómeno de desjudicialización. Resulta llamativo de este documento institucional, que desde el gobierno se impulse una reforma para desjudicializar en asuntos de familia, comerciales, laborales, agrarios y civiles, sin sustituir la justicia ordinaria, sino como forma para brindar mayor acceso al sistema judicial ${ }^{31}$.

Un sector de la doctrina justificó la función jurisdiccional otorgada, a partir de la eficiencia ${ }^{32}$ de este organismo en la resolución los conflictos ${ }^{33}$, dado que para entonces el país se abría a un proceso de apertura económica. Entretanto, otro sector ${ }^{34}$ calificó dicha atribución como un efecto derivado de un compromiso internacional del gobierno con instituciones

\footnotetext{
${ }^{24}$ REPÚBLICA DE COLOMBIA. ASAMBLEA NACIONAL CONSTITUYENTE (1991a), p. 147

${ }^{25}$ REPÚBLICA DE COLOMBIA. ASAMBLEA NACIONAL CONSTITUYENTE (1991b), p. 10.

${ }^{26}$ BALLEN et al. (2018), p. 71.

27 REPÚBLICA DE COLOMBIA. ASAMBLEA NACIONAL CONSTITUYENTE (1991b), p.p. 75-78.

28 DECRETO 2651/1991, de noviembre 25, Artículo 32. Corte Constitucional. C-592/1992.

29 JULIO (2002), p. 276.

${ }^{30}$ En relación a las reformas judiciales adelantadas hacía el inicio de la década de los noventas, se afirma por un sector, que estas obedecieron a compromisos tanto del gobierno nacional con instituciones financieras internacionales como el Banco Mundial y el Fondo Monetario Internacional para agilizar sus aparatos judiciales y modernizarlos. VÁSQUEZ (2014), p. 83. Otros afirman que las formas implementadas en materia de justicia en nuestro país, con financiamiento internacional arrancaron en los años ochenta a través de la Agencia Internacional de Desarrollo (AID) de los Estados Unidos, hacia 1986 en el Gobierno liberal de Virgilio Barco, y las reformas que tuvieron lugar en el gobierno del Presidente Cesar Gaviria Trujillo, también liberal, se produjeron con ocasión a ayudas internacionales que desde la década de los ochentas venían. NEMOGÁ (1995), p. 121

${ }^{31}$ REPÚBLICA DE COLOMBIA. MINISTERIO DE JUSTICIA Y DEL DERECHO (1994), p. 109.

${ }^{32}$ REYES (1992), p. 84.

${ }^{33}$ Decreto 350/1989, de febrero 16, Artículos 50 y 52.

${ }^{34}$ VÁSQUEZ (2014), p. 83.
} 
financieras internacionales para mejorar el sistema judicial, que para entonces era lento, congestionado y necesitaba modernizarse.

De todas maneras, se resalta que para la época algunos ${ }^{35}$ llamaron la atención sobre el peligro que representaba atribuir dichas funciones; al punto de preguntarse si era peligroso abrirle paso, al hecho que la administración juzgara a los ciudadanos, abandonándose la tradicional función de aquella de mantener el orden público y ejecutar en forma coercitiva las disposiciones legales.

De otra parte, la ley $222 / 1995^{36}$ otorga funciones jurisdiccionales a las Superintendencia de Sociedades para procesos concursales, de manera privativa ${ }^{37}$, sustentándolo en el artículo 116.

Para 1996, se expide la primera ley estatutaria de administración de justicia, ley 270/1996, que impone la obligación en cabeza del Consejo Superior de la Judicatura ${ }^{38}$, de elaborar el plan sectorial para la Rama Judicial en el que se incluyeron los lineamientos generales para que organismos de carácter administrativo desplegaran funciones de estirpe jurisdiccional y su cohesión con el sistema de justicia impartido por la rama judicial, con la finalidad de lograr el acceso real de los ciudadanos a la administración de justicia y la eliminación de la congestión judicial ${ }^{39}$. Sin embargo, ello no ocurrió, pues los acuerdos del Consejo Superior de la Judicatura no se ocuparon del tema ${ }^{40} 41$.

Otro aspecto a destacar en este periodo es que la ley estatutaria consagró la alternatividad $^{42}$, que hacía referencia a formas de solución de conflictos diferentes al proceso judicial. Sin embargo, parece inferirse que esta correspondía a formas alternas de solución de conflictos como la conciliación; aunque para entonces algunos ${ }^{43}$ identificaron que el ejercicio de la función jurisdiccional por autoridades del sector ejecutivo, estaban comprendidas en el principio de alternatividad.

Segundo estadio (1998-2011): Altos y bajos de un proceso de empoderamiento continúo en materia de oferta de administración de justicia

Esta etapa es la más larga y rica en pronunciamientos del legislador y de la Corte Constitucional sobre el objeto de análisis. Por este motivo, se ha dividido en tres apartados el análisis, dado la extensión de los hechos y las novedades legislativas que se produjeron en torno al tema. Este periodo se encuentra marcado por la ley 446/1998 y cierra con la ley 1450/2011, que otorga más funciones jurisdiccionales al ejecutivo. Justificándose este otorgamiento en la necesidad de: descongestionar el poder judicial, el conocimiento técnico de estas autoridades y el fortalecimiento de la oferta de administración de justicia, entendido como mecanismo alternativo de solución de conflictos.

Primer periodo: De las motivaciones del legislativo, a la necesidad de darle contenido a esta forma de justicia por parte de la Corte Constitucional (1998-2002)

\footnotetext{
35 BOTERO (1995), p. 46.

${ }^{36}$ Ley 222/1995, de diciembre 20, Artículo 90.

${ }^{37}$ La tendencia legislativa al desarrollar esta preceptiva constitucional es a otorgar la atribución de función jurisdiccional en autoridades administrativas a prevención y no en forma privativa.

38 Ley 270/1996, de marzo 7, Artículo 85. Funciones administrativas.

39 Ley 270/1996, de marzo 7, Artículo 87. Plan de desarrollo de la rama judicial.

${ }^{40}$ El primer acuerdo expedido por el Consejo Superior de la Judicatura, data de 1996, sin embargo, en este nada se dijo sobre el otorgamiento de funciones jurisdiccionales como mecanismo para realizar descongestión. REPÚBLICA DE COLOMBIA, CONSEJO SUPERIOR DE LA JUDICATURA. SALA ADMINISTRATIVA (1996).

${ }^{41}$ REPÚBLICA DE COLOMBIA, CONSEJO SUPERIOR DE LA JUDICATURA. SALA ADMINISTRATIVA (1998).

42 Ley 270/1996, de marzo 7.

${ }^{43}$ FUENTES y PERAFÁN (2003), p. 250.
} 
Esta etapa se caracteriza por la promulgación de la ley 446/1998 que justifica esta forma de justicia en la necesidad de descongestionar el poder judicial e igualmente en el conocimiento técnico de estas autoridades. Para el caso del poder judicial, fue la Corte Constitucional, en ejercicio de sus funciones, el órgano que, poco a poco, inició el camino de desentrañar el contenido, alcance y limitaciones de esta actividad del Ejecutivo. Resaltándose que el órgano administrativo del poder judicial continúa haciendo caso omiso del tema.

De esta manera, ley 446/1998 contempla este tipo de justicia ${ }^{44}$, concebida como forma de descongestión judicial, aun cuando en la exposición de motivos se señala que esta ley obedece a los conocimientos técnicos de dichas entidades ${ }^{45}$. Esta disonancia en las motivaciones del otorgamiento de las competencias propiamente judiciales a organismos administrativos, se nota igualmente cuando el promotor de la ley, y entonces Ministro del Interior, señalara que las facultades jurisdiccionales radicadas en cabeza de las Superintendencias no tuvieron jamás por finalidad la descongestión judicial ${ }^{46}$. Tampoco se aclaró el panorama cuando el Consejo Superior de la Judicatura, en el plan sectorial de desarrollo 1999-2002 ${ }^{47}$, se ocupa de esta forma de justicia como una de las herramientas para enfrentar la congestión judicial.

En esta primera parte del periodo, la Corte Constitucional, a partir del estudio de constitucionalidad de la ley 446/1998, comienza a darle forma a esta actividad de la administración. Para el caso, enfatiza en que la oferta de justicia otorgada a las autoridades administrativas ${ }^{48}$ se ejerce a prevención ${ }^{49}$. Es decir, que las competencias judiciales que ejercen estas autoridades son las mismas que ejercen los jueces de la jurisdicción ordinaria ${ }^{50}$. Ubicando la activación del ejercicio de funciones jurisdiccionales del poder ejecutivo en una decisión del accionante. Así, acudir a esta oferta de justicia no depende de la materia, el órgano u otra calificación legal, lo que a juicio de la doctrina es erróneo ${ }^{51}$, sino de la pretensión del actor.

Luego, se modifica las competencias de la ley 446/1998, a través de la ley 510/199952, cuya constitucionalidad fue avalada bajo el entendido que las funciones en materia jurisdiccional son permanentes conforme a la constitución, pero a la vez, excepcionales. Ese mismo año, fue expedida la ley $550^{53}$ que fija funciones jurisdiccionales en cabeza de la Superintendencia de Sociedades, en diversas materias. Competencias estas últimas, cuya constitucionalidad no fue impugnada en sede constitucionalidad, como había ocurrida hasta entonces, con todas las leyes que habían asignado competencias jurisdiccionales a las Superintendencias.

Para ese momento, la Corte reiteró que el legislador dentro de su margen de libertad configurativa puede contemplar recursos contra estas decisiones jurisdiccionales. Situación que generó fuertes críticas $^{54}$, en la vía que esto hacía perder la especialidad de la decisión tomada por la Superintendencia y rompía la razón de ser de esta forma de justicia, pues el pronunciamiento de un especialista (Superintendencia) debía ser resuelto por un generalista (juez), así como la agilidad de esta justicia. Considerando que el término "ante las mismas" debía entenderse que el recurso de apelación era ante la misma Superintendencia, pues no concebía que por vía de recurso de apelación, una decisión jurisdiccional fuera conocida por un juez. En todo caso contra estas es procedente la acción de tutela ${ }^{55}$, siempre y cuando concurran las causales genéricas de procedibilidad de la acción constitucional.

Además, la Corte señaló en temas de organización de la Administración, que no necesariamente el funcionamiento de esta justicia debía ser desconcentrado cómo sí funciona

\footnotetext{
${ }^{44}$ CRUZ (2014), p. 67.

${ }^{45}$ REPÚBLICA DE COLOMBIA. CONGRESO DE LA REPÚBLICA DE COLOMBIA (1998) pp. 113-115.

${ }^{46}$ MARTÍNEZ (2002), pp. 235-238.

${ }^{47}$ REPÚBLICA DE COLOMBIA, CONSEJO SUPERIOR DE LA JUDICATURA. SALA ADMINISTRATIVA (1998).

${ }^{48}$ Corte Constitucional. C-833/2006.

${ }^{49}$ Corte Constitucional. C-1071/2002; Corte Constitucional. C-649 de 2001.

${ }^{50}$ Corte Constitucional. C-649/2001.

${ }^{51}$ DUSSAN (2005), p. 715.

52 Ley 510/1999, de agosto 3, Artículo 52.

53 Ley 550/1999, de diciembre 30, Artículos37-39.

${ }^{54}$ ARCHILA (2002), pp. 61-63.

${ }^{55}$ Corte Constitucional. C-384/2000.
} 
la estructura de la rama judicial, y que si bien existía una jerarquía solamente de carácter funcional en la rama judicial, la jerarquía orgánica de la administración pública en general, no trastocaba o afectaba la función judicial en cuanto a su autonomía e independencia ${ }^{56}$.

En este periodo también se forja en la jurisprudencia, el concepto de independencia del funcionario que como integrante del ejecutivo, ejerce la función jurisdiccional, señalándose la separación de funciones administrativas de las jurisdiccionales, dado que no es admisible la confusión de funciones en un mismo funcionario ${ }^{57}$. Anotándose por parte del Consejo de Estado, que la atribución de funciones jurisdiccionales era una medida de descongestión, y de justicia a prevención ${ }^{58}$.

Igualmente, en este periodo, se producen varios pronunciamientos en donde se estudió la procedencia de acciones de tutela, contra decisiones de las Superintendencias en desarrollo de funciones jurisdiccionales, señalándose que esta era procedente cuando se presentara una vía de hecho, excepcionalmente. Declarándose improcedente cuando existiera otro medio de defensa judicial ${ }^{59}$.

Finalmente, fue en esta etapa en donde la jurisprudencia hizo una categorización para estimar cuando una disposición legislativa que asignaba competencias judiciales a entidades administrativas era constitucional o no, determinando que: i) es constitucional si separa y distingue claramente las funciones administrativas de las jurisdiccionales y no hay riesgo de interferencia entre unas y otras ${ }^{60}$; ii) no será inconstitucional la norma, si a pesar de la confusión entre las funciones administrativas y jurisdiccionales, desde el punto de vista práctico y jurídico se puede superar tal confusión o interferencia entre una y otra función, pero solo bajo ese entendido ${ }^{61}$. Criterio este último, que, parece determinar un contorno tan flexible y elástico, para la identificación constitucional de las funciones jurisdiccionales a autoridades administrativas, que parece quedar a discreción del legislador y de la jurisprudencia, la determinación de cuando son viables o no la atribución de estas funciones.

En este periodo un sector de la doctrina hace hincapiéb2, en que el debido proceso debía aplicarse con mayor rigor en esta forma de justicia, porque al no haber regulación expresa para el trámite jurisdiccional en estos eventos, debía acudirse, en primer lugar, al código contencioso administrativo en su primera parte; y en segundo lugar, al proceso verbal sumario que establecía el código de procedimiento civil $^{63}$. Exigencia que tal vez podía considerarse un tanto razonable, pero que generó confusión en la sociedad ${ }^{64}$ al no saberse con precisión si los asuntos decididos por las Superintendencias, como autoridad jurisdiccional, eran controlados por el juez contencioso o por el juez civil ${ }^{65}$.

Segundo periodo (2002-2006): Interés de la doctrina de la Corte Constitucional y científica vs. apatía de los poderes públicos frente al tema

Fue la doctrina científica, la que de una parte, se ocupa de analizar esta cuestión y por otro lado, la Corte Constitucional continuó el camino de definir los lineamientos de actividad

\footnotetext{
${ }^{56}$ Corte Constitucional. C-833/2006.

57 Corte Constitucional. C-1641/2000; C-1143/2000; C-649/2001; C-384/2000.

${ }^{58}$ Consejo de Estado. Sala de Consulta y Servicio Civil. Abril 11 de 2002. C.P. Dra. Susana Montes.

${ }^{59}$ Corte Constitucional. T-279/1999; T-494/1999.

${ }^{60}$ Corte Constitucional. C-1641/2000; C-649/2001.

${ }^{61}$ Corte Constitucional. C-415/2002. Reiterada en: C-896/2012; C-156/2013.

62 DUSSAN (2005), p. 716

63 Ley 446/1998, de julio 7, Artículo 148.

${ }^{64}$ CRUZ (2014), p. 80

${ }^{65}$ Consejo de Estado. Sala De Lo Contencioso Administrativo. Sección Primera. Consejero ponente: Manuel Santiago Urueta Ayola. Bogotá, D. C., Auto de veintiocho (28) de noviembre del dos mil dos (2002). Radicación número: 2500023240002001791601 (7916). Actor: Comunicación Celular S.A. Comcel S.A; Consejo de Estado. Sala De Lo Contencioso Administrativo. Sección Primera. Consejero ponente: Camilo Arciniegas Andrade. Bogotá D.C., seis (6) de agosto de dos mil cuatro (2004). Radicación número: 2500023-24-000-2003-0341-01. Actor: S.O. Colombia Limitada. Demandado: Superintendencia De Industria y Comercio. Referencia: Apelación Interlocutorio.
} 
jurisdiccional de la administración. Situación que contrasta con el silencio desde el ejecutivo, legislativo y los órganos administrativos del poder judicial.

Así en el plano de la doctrina se producen críticas a esta forma de justicia, impulsadas por aires de reforma, encaminadas en el hecho que en un estado de derecho el gobernante no podía suplir al juez, y que si bien esta estrategia de desjudicialización podía operar para asuntos menores o pequeñas reclamaciones, tal premisa no se aplicaba para grandes pleitos ${ }^{66}$. En esa misma línea, otros autores sostienen que el desplazamiento de funciones jurisdiccionales tenía como motivación velada, el tratar de ejercer un control sobre la justicia ${ }^{67}$.

No obstante ese escenario, se destaca el hecho que se concibe que este tipo de justicia no era de élites, pues también se ha instituido para "pequeñas reclamaciones" 68 que interesan al ciudadano de a pie, como en las asuntos de consumo, por ejemplo. Al punto, que desde la academia y la Superintendencia de Sociedades, algunos se atreven a señalar que desde hace más de una década, la jurisprudencia en materia de sociedades no se halla en el órgano de cierre ni en los tribunales de la jurisdicción ordinaria, sino en la Delegatura para asuntos jurisdiccionales de esa entidad ${ }^{69}$.

Dado el reconocimiento que se han venido forjando las superintendencias en la administración de justicia, un sector de la doctrina ${ }^{70}$ se opuso a fusionar las instituciones, ya que ellas demostraban que en algunas materias, eran estas quienes producían la verdadera jurisprudencia, y no los jueces del poder judicial.

En este periodo se dejó sentado que es constitucional que las funciones de control, inspección y vigilancia junto con las jurisdiccionales pudieran ejercerse sobre un mismo asunto, siempre que la estructura de la entidad permita la imparcialidad del funcionario en los asuntos judiciales. Comprendiéndose, desde entonces, que un funcionario que ejerce funciones de inspección, vigilancia y control no puede posteriormente, o en forma concomitante, realizar la actividad jurisdiccional respecto al mismo asunto ${ }^{71}$.

En esta etapa, se clarificó que solo se podía delegar el ejercicio de función jurisdiccional en autoridades que hicieran parte del ejecutivo y que en sentido subjetivo u orgánico tuvieran la condición de autoridades administrativas ${ }^{72}$ por tener a su cargo de manera permanente el ejercicio de actividades y funciones de naturaleza administrativa ${ }^{73}$. Estando prohibido otorgar dichas facultades a autoridades distintas a estas o a particulares que cumplieran funciones administrativas como los notarios ${ }^{74}$.

Todo lo anterior contrasta con la Ley del Plan de Desarrollo del gobierno de la época (2002-2006) ${ }^{75}$, que a pesar de considerar la implementación de mecanismos para facilitar el acceso de los ciudadanos a la administración de justicia, nada expresó respecto a la atribución de funciones jurisdiccionales a autoridades pertenecientes al ejecutivo. Silencio que también se extendió al Plan Sectorial de Desarrollo para la Rama Judicial 2003-200676. De todas maneras, existieron intentos por modificar algunos aspectos de las funciones jurisdiccionales de autoridades administrativas, a instancias de proyectos de ley, luego integrados en uno solo, presentados por el Consejo Superior de la Judicatura ${ }^{77}$; el gobierno nacional a través del Ministro del Interior y de Justicia ${ }^{78}$, y por parte de congresistas, que finalmente fueron archivados ${ }^{79}$.

\footnotetext{
${ }^{66}$ MARTÍNEZ (2002), pp. 235-238.

67 CASTAÑO (2006), p. 172.

68 MARTÍNEZ (2003), p.157.

${ }^{69}$ REYES (2018).

${ }^{70}$ REYES (2002), pp. 203-206.

${ }^{71}$ Corte Constitucional. Sentencia C-1071/2002.

${ }^{72}$ Corte Constitucional. Sentencia C-1159/2008.

73 Ley 489/1998, de julio 7, Artículo 39.

${ }^{74}$ Corte Constitucional. C-1159/2008. Posición reiterada en: C-863/2012.

75 Ley $812 / 2003$, de junio 26, Artículo 8․

76 REPÚBLICA DE COLOMBIA, CONSEJO SUPERIOR DE LA JUDICATURA. SALA ADMINISTRATIVA (2002).

77 REPÚBLICA DE COLOMBIA, CONGRESO DE LA REPÚBLICA DE COLOMBIA (2004a) pp. 29-31.

78 REPÚBLICA DE COLOMBIA. CONGRESO DE LA REPÚBLICA DE COLOMBIA (2004b).

79 REPÚBLICA DE COLOMBIA. CONGRESO DE LA REPÚBLICA DE COLOMBIA (2004c).
} 
Tercer periodo (2007-2011): Mucho ruido y pocas nueces, aumento del número de autoridades y competencias sin logar aún un sistema estructurado

Esta etapa se encuentra marcada por el empoderamiento de las superintendencias, e igualmente por la inclusión del tema en la agenda del ejecutivo y del legislativo; sin embargo no se logra concretar su regulación, desaprovechándose las distintas oportunidades que se ocuparon de la administración de justicia. En las pocas referencias a la cuestión, que se hicieron en este periodo, uno de los argumentos empleados para justificarlos, fue el relativo con los mecanismos alternos de solución de conflictos.

Entonces, esta etapa se parte de un silencio en el Plan de Desarrollo (2006-2010) ${ }^{80}$, a pesar de considerar la implementación de mecanismos para facilitar el acceso de los ciudadanos a la administración de justicia. Esta situación fue documentada posteriormente por un ex presidente del Consejo de Estado ${ }^{81}$, dejando en evidencia que para el gobierno de entonces la justicia no era una prioridad estratégica en su concepción de Estado, siendo una de las causas de la crisis democrática en el país. Y como ha sido la costumbre, este tema pasa inadvertidamente, una vez más, en el Plan Sectorial de Desarrollo de la Rama Judicial 2007-2010.

En este periodo, hay un aumento importante de competencias que se le otorgan a las Superintendencias, por un lado se les empodera a nuevas entidades de esta función y en otros casos se les asigna más competencias. En el primer caso, esta la Superintendencia la Nacional de Salud ${ }^{82}$, a quien se le crea una dependencia denominada delegada para la función jurisdiccional y la conciliación ${ }^{83}$. Posteriormente, el legislador, en el 2008, otorgó nuevas funciones jurisdiccionales a la Superintendencia de Sociedades en materia societaria, en la ley de creación de las sociedades por acciones simplificadas SAS, fundamentándose de manera expresa en el artículo 116 constitucional ${ }^{84}$.

Este aumento de funciones, se nota también, en los años 2010 y 2011, cuando se asignan nuevas competencias en materia jurisdiccional a la Superintendencia de Sociedades ${ }^{85}$, y la Superintendencia Nacional de Salud ${ }^{86}$, aclarándose sus funciones y extendiendo su competencia a nuevos asuntos, regulándose expresamente lo relativo a las medidas cautelares ${ }^{87}$. Para el supuesto de la Superintendencia Financiera, ley 1480 de 2011 amplía competencias en materia jurisdiccional, para el consumidor financiero en materia aseguradora, bursátil y financiera ${ }^{88}$, y a la Superintendencia de Industria y Comercio en temas de protección al consumidor ${ }^{89}$. Determinado hasta entonces un procedimiento especial para estos asuntos. Señalando innovaciones para el ejercicio de estas funciones jurisdiccionales como la posibilidad de fallar ultra, extra e infra petita ${ }^{90}$. Así como también de imponer sanciones, consideradas por un sector de la doctrina como actos administrativos ${ }^{91}$, dentro de la providencia que recoge la sentencia que esa entidad dicta como autoridad jurisdiccional ${ }^{92}$.

Otro hito dentro de este periodo, ocurre con la expedición de la ley estatutaria 1285/200993, que reiteró el argumento de que esta forma de administrar justicia es un mecanismo para fortalecer la oferta de justicia ofrecida por el Estado, pero comprendido en esta

\footnotetext{
${ }^{80}$ Ley $1151 / 2007$ de julio 24, Artículo $6^{\circ}$.

${ }^{81}$ APONTE (2014), p. 368.

82 Ley 1122/2007, de enero 9, Artículo 41.

83 Decreto 1018/2007, de marzo 30 Artículo 22.

${ }^{84}$ Ley $1258 / 2008$, de diciembre 5, Artículo 44.

${ }^{85}$ Ley 1429/2010, de diciembre 29, Artículo 29.

${ }^{86}$ Ley $1438 / 2011$, de enero 18.

87 Ley 1438/2011, de enero 18, Artículos 126-127.

88 Ley 1480/2011, de enero 18, Artículo 57.

${ }^{89}$ Ley 1480/2011. De enero 18, Artículo 58.

${ }^{90}$ Corte Suprema de Justicia. Sala de Casación Civil. Sentencia radicada: SC3085-2017. Providencia de 7 de marzo de 2017.

Expediente: 08001-31-03-004-2007-00233-01. Magistrado Ponente: Álvaro Fernando García Restrepo.

${ }^{91}$ TORREGROSA (2018), p. 136

92 Corte Constitucional. C-561 de 2015. Magistrada Ponente: María Victoria Calle Correa.

${ }^{93}$ Ley $1285 / 2009$, de enero 22, Artículo 3.
} 
ocasión bajo el rotulo de mecanismo alternativo de solución de conflictos. Además se ordena la creación de una comisión del proceso oral y por audiencias que tuvo por función la de presentar proyectos de desjudicialización y de otorgamiento de funciones jurisdiccionales a autoridades administrativas, de la cual no se tiene noticia. Situación que fue criticada fuertemente por un sector de la doctrina, debido al carácter político de las autoridades, que colocaban en entredicho los principios de autonomía e independencia judicial ${ }^{94}$.

Luego en el año 2010 se expide la ley 1395 dedicada a la descongestión judicial, convirtiéndose en otra oportunidad no aprovechada para referirse a este tipo de justicia. En su exposición de motivos, se indica que uno de sus objetivos es el de contrarrestar la sobrecarga de trabajo existente en los juzgados, a través de instrumentos como la simplificación de trámites judiciales, y la de desjudicializar los conflictos ${ }^{95}$. Limitándose a contemplar, para el caso en concreto, a que el procedimiento en los procesos surtidos antes el poder judicial sería aplicable igualmente ante dichas autoridades ${ }^{96}$.

El otorgamiento de más funciones jurisdiccionales al ejecutivo se vio reflejado en el plan de desarrollo 2010-2014, ley 1450/2011, aun cuando por distintas razones, algunos asuntos no tuvieron lugar. Entonces la ley en mención dispuso la expedición de un documento CONPES Consejo Nacional de Política Económica y Social- que emitiera recomendaciones para garantizar el ejercicio de funciones jurisdiccionales por parte de autoridades administrativas ${ }^{97}$, el cual tampoco vio la luz. Así mismo, se otorgaron facultades al Ministerio del Interior y de Justicia, para conocer de asuntos jurisdiccionales ${ }^{98}$, aunque dichas facultades luego fueron subrogadas por el Código General del Proceso y posteriormente declaradas inconstitucionales ${ }^{99}$. Igualmente esta normatividad, amplió la competencia de la Superintendencia de Sociedades a todas las sociedades sujetas a su supervisión ${ }^{100}$.

Para finales de este periodo, la doctrina especializada en temas de justicia ${ }^{101}$, parecía inclinarse a la opinión que el problema de la administración de la justicia en el país, se concentra en el asunto del acceso a la oferta de administración de justicia ${ }^{102}$ y el cumplimiento material o efectividad de la decisión judicial; sin que esos estudios se ocuparan de la atribución de funciones jurisdiccionales en autoridades administrativas ${ }^{103}$. No obstante, existe evidencia ${ }^{104}$ que la política de descongestión judicial implementada, basada en la creación de más despachos judiciales y de cargos de funcionarios y empleados entre los años 2010 y 2013, no arrojó resultados positivos en la lucha contra la disminución del atrasado y congestión judicial existente ${ }^{105}$

Tercer estadio, (2012- 2018): Pese al interés suscitado en los poderes públicos, resta camino por andar

Esta etapa se encuentra marcada por el aumento de autoridades administrativas con funciones jurisdiccionales, la expedición del código general del proceso, y los pronunciamientos el ejecutivo y el judicial en la materia.

Este periodo se marca con un hito, como fue la expedición del Código General del Proceso ${ }^{106}$, texto que agrega dos (2) nuevas entidades (Instituto Nacional Agropecuario -ICA-

\footnotetext{
${ }^{94}$ ROJAS (2009), p. 771.

95 REPÚBLICA DE COLOMBIA. CONGRESO DE LA REPÚBLICA DE COLOMBIA (2008), p.7.

${ }^{96}$ VÁSQUEZ (2011), p. 8.

${ }^{97}$ Ley $1450 / 2011$, de junio 16, Artículo 197. Literal d.

98 Ley 1450/2011, de junio 16, Artículo 199.

${ }^{99}$ Corte Constitucional. C-156 de 2013.

100 Ley 1450/2011, de junio 16, Artículo 252.

${ }^{101}$ ACOSTA (2010), p. 200.

102 VARGAS (2013), p. 330; ACOSTA (2010), p. 201.

103 TORRES (2015), 125

104 REPÚBLICA DE COLOMBIA. CONTRALORÍA GENERAL DE LA REPÚBLICA (2014), pp. 31-33.

${ }^{105}$ REPÚBLICA DE COLOMBIA. CONTRALORÍA GENERAL DE LA REPÚBLICA (2014), p. 42.

106 Ley 1564/2012, de julio 12, Artículo 24.
} 
y la Dirección Nacional de Derechos de Autor -DNA-), del orden nacional al rompecabezas de autoridades con funciones de esta naturaleza. Reiterando las funciones ya otorgadas al Ministerio del Interior y de Justicia, que fueron posteriormente declaradas inconstitucionales ${ }^{107}$. Además de adicionar, reagrupar funciones de este tipo que tenían las superintendencias de sociedades, financiera y de industria y comercio. Sin que exista una explicación en los antecedentes de la ley, sobre el por qué no se incluyó en esta a la superintendencia de salud.

No obstante, el código no reguló por materia sino por autoridad, las funciones jurisdiccionales otorgadas a autoridades del ejecutivo, y tampoco derogó otras competencias atribuidas a estas en leyes especiales ${ }^{108}$, por lo que no es esta codificación un marco en el que estén totalizadas las funciones jurisdiccionales de autoridades administrativas ${ }^{109}$.

Entre las motivaciones del Código para regular y expandir la función jurisdiccional de estas autoridades, se encuentra la necesidad de solucionar problemas graves como la celeridad y falta de solución efectiva de conflictos existentes en la rama judicial. Hechos que se sustentaron en informes del Banco mundial, del Foro Económico Mundial, rankings e indicadores internacionales, y de estudios nacionales, sobre acceso a la justicia, celeridad, congestión judicial y eficiencia del marco legal para resolver disputas ${ }^{110}$.

Algún sector de la doctrina afirmó que este código tenía como objetivo, la búsqueda de un eficientísimo procesal de espaldas al ciudadano de a pie, y de volver la justicia nacional en una de las más rápidas del mundo ${ }^{111}$, continuando con experiencias procesales de otros ordenamientos jurídicos ${ }^{112}$.

Por su lado, la Corte justificó estas funciones en: i) la función orgánica, esto es, el desarrollo del principio de colaboración armónica de los poderes públicos; y, ii) en las garantías propias de la administración de justicia, en particular, las de acceso a la administración de justicia y del debido proceso ${ }^{113}$.

Al revisar el cuerpo normativo se encuentra que el legislador se ocupó de regular el tema siguiendo la jurisprudencia existente, cerrando la discusión en torno a que un mismo asunto se tramitara de igual forma, con simetría procesal ${ }^{114}$, sin consideración a que fuera atendido por un juez de la administración o de la rama judicial ${ }^{115}$. E igualmente llevó a norma de rango legal, reglas jurisprudenciales ${ }^{116}$ antes trazadas de forma asimétrica, tales como: i) la competencia jurisdiccional a prevención de estas autoridades; ii) el principio de inmediación; iii) la gradualidad en la oferta de esta justicia; $y$, iv) el control judicial de estas decisiones mediante recurso de apelación ante el superior funcional del juez desplazado, con la previsión que en los asuntos de mínima cuantía no cabe el recurso de apelación.

A pesar de todo lo anterior, el avance propuesto por el código en la materia no fue organizado y con proyección, pues a pesar de su deseo de sistematizar esta forma justicia, establecer reglas para actuar ante ella, y enlistar a estas autoridades, aunque no incluyó a todas, pasó por alto aspectos vitales para su consolidación. Ello se evidencia, al no incluirse un plan de acción para su implementación ${ }^{117}$, como tampoco la incorporación de al menos un

\footnotetext{
107 Corte Constitucional. C-156/2013.

${ }^{108}$ CRUZ (2014), p. 71.

${ }^{109} \mathrm{Al}$ respecto, encontramos que en el informe de ponencia para primer debate del proyecto de ley número 159 de 2011 Senado, 196 de 2011 Cámara, por la cual se expide el Código General del Proceso y se dictan otras disposiciones, se expresó: Adicionalmente, regula las actuaciones procesales de las autoridades administrativas y de los particulares investidos de funciones jurisdiccionales, en aquellos asuntos no regulados expresamente en otras disposiciones legales. REPÚBLICA DE COLOMBIA. CONGRESO DE LA REPÚBLICA DE COLOMBIA (2012), p. 1.

${ }^{110}$ REPÚBLICA DE COLOMBIA. CONGRESO DE LA REPÚBLICA DE COLOMBIA (2012), p. 2-3.

${ }^{111}$ VÁSQUEZ (2014), pp. 83-84.

112 Informe de ponencia para primer debate del proyecto de ley número 159 de 2011 Senado, 196 de 2011 Cámara, por la cual se expide el Código General del Proceso y se dictan otras disposiciones. REPÚBLICA DE COLOMBIA. CONGRESO DE LA REPÚBLICA DE COLOMBIA (2012), p. 2.

113 Corte Constitucional. C-436 de 2013.

114 ÁLVAREZ (2018), p. 49.

115 ÁLVAREZ (2013), p. 127.

116 Corte Constitucional. C-436/2013.

117 Ley 1564/2012, de julio 12, Artículo 618.
} 
representante de estas entidades en la comisión de seguimiento para la implementación de este código ${ }^{118}$.

Al año siguiente de la expedición del código general del proceso, se continua con la expansión de funciones jurisdiccionales en cabeza de autoridades administrativas, con la expedición de la ley 1676/2013 ${ }^{119}$, sobre garantías mobiliarias, que parece permitir la presentación de un proceso de naturaleza ejecutiva, ante la Superintendencia de Sociedades, cuando el garante o deudor de una garantía mobiliaria sea una sociedad sometida a su vigilancia, para conocer de la adjudicación o realización especial de la garantía real ${ }^{120}$ o de ejecución especial de la garantía ${ }^{121}$.

Luego vino un periodo de calma en cuanto a la expedición de medidas legislativas en este tema, hasta la expedición del Decreto 1817/2015, que determinó que el nombramiento de algunos Superintendentes que tenían a su cargo Superintendencias con funciones jurisdiccionales, a pesar de ser cargos de libre nombramiento remoción, tendrían el mismo periodo del Presidente de la República, tal vez con el fin de "asegurar la competencia profesional, imparcialidad, transparencia e independencia" del cargo de Superintendente. Sin embargo, esto parece no garantizar la autonomía de un juez cuando la función judicial es ejercida por quien está sometido laboralmente a órganos superiores que tienen poderes de libre nombramiento y remoción y disciplinarios sobre dicho funcionario ${ }^{122}$.

A la fecha, no está del todo claro si los empleos de los Superintendentes son de periodo fijo o de libre nombramiento y remoción ${ }^{123}$. Se resalta que esta decisión se tomó solamente respecto a unas Superintendencias (a excepción de la de salud), y no se extendió a todas las entidades del orden nacional, o al menos, a las que tienen atribuidas funciones jurisdiccionales (por ejemplo: el ICA, la DNA o el ICBF, esta última que cuenta con defensores de familia que tienen esta función).

En este periodo se crea una especie de incidente de desacato, a través de la Ley $1797 / 2016^{124}$, para garantizar el cumplimiento de las decisiones jurisdiccionales proferidas por la Superintendencia Nacional de Salud, dada la prohibición de conocer de procesos de ejecución frente a sus propias decisiones, y por la falta de competencia legal para hacer cumplir sus propias decisiones. Esto parece sugerir que una parte del éxito de las funciones de estas autoridades está en que ellas mismas puedan garantizar su cumplimiento, de manera forzada o coercitiva, imponiendo sanciones a quien las inobserve. Sin embargo, en esta materia con la expedición de la Ley $1949 / 2019^{125}$ se trataron de corregir algunos vacíos, en cuanto al procedimiento existente, excluyendo algunos asuntos para ser ventilados a través de este trámite, y ampliando los términos de decisión de estos. No obstante, aún no existe un término legal para resolver las apelaciones, lo que ha llamado la atención de la jurisprudencia ${ }^{126}$.

Cabe señalar que no hay estudios que comparen la eficacia de esta forma de justicia con respecto a la ofrecida desde la rama judicial ${ }^{127}$, lo que ha sido también advertido por la doctrina ${ }^{128}$. En favor de este silencio, debe señalarse que no existen métodos o parámetros para la recolección de estos datos, establecidos en la ley. Prueba de ello se observa en el plan sectorial de desarrollo de la rama judicial 2015-2018 ${ }^{129}$, que muestra la desconexión tanto política como institucional de la oferta de justicia que se imparte desde la rama judicial, con respecto a la ofrecida por los entes administrativos con facultades de naturaleza jurisdiccional.

\footnotetext{
118 Ley 1564/2012, de julio 12, Artículo 619.

119 Ley 1676/2013, de agosto 20, Artículo 57-58.

${ }^{120}$ Ley 1564/2012, de julio 12, Artículo 467.

${ }^{121}$ Ley 1564/2012, de julio 12, Artículo 468.

122 CAMPOS (2014), p. 124.

123 Decreto 1817/2015, de septiembre 15, Artículo 1.

124 Ley 1797/2016, de julio 13, Artículo 25.

125 Ley 1949/2019, de enero 8, Articulo 6.

${ }^{126}$ Corte Constitucional. T-603 de 2015.

127 PODER JUDICIAL (2016), p. 167.

${ }^{128}$ CUERVO (2013), p. 68

${ }^{129}$ CUERVO (2015), p. 43
} 
Contrario a esto, el plan de desarrollo "todos por un nuevo país", recogido en la Ley 1753/ $2015^{130}$, hace una ruptura en este camino, y con el objeto de coordinar los diferentes sistemas de justicia, y promover la eficacia y eficiencia de estos, ordena a todos los actores, haciendo mención general de las autoridades administrativas que tienen funciones jurisdiccionales, que realicen un plan decenal de justicia, a cargo del Ministerio de Justicia y del Derecho, denominado también plan interinstitucional, que englobe a todos los actores del sistema de justicia, señalando objetivos comunes e incentivos para todas estas autoridades. Pero, no se estableció obligación alguna en relación a las entidades mencionadas ${ }^{131}$, otra oportunidad desaprovechada.

\section{Conclusiones}

El empoderamiento, los últimos veintiocho años, a las autoridades administrativas ha sido un proceso a muchas velocidades y con distintos actores; que desde su origen no ha respondido a un trabajo conjunto, cohesionado articulado y meditado; sino a prisas y necesidades sectoriales y coyunturales. Contrastando el incremento de funciones a dichas entidades, frente al interés apenas notorio de las partes que concurren en un tema de vital interés para la convivencia como es la administración de justicia.

Se destaca las oportunidades desaprovechadas por el legislativo, en las distintas reformas a la justicia, de diseñar un sistema que defina y determine el verdadero alcance del todo y sus partes de estar forma de resolver controversias. Asimismo se subraya el silencio de los órganos administrativos del poder judicial que ha omitido comentario sobre la materia. En contraste los tribunales de cierre constitucional sí han cumplido indirectamente con esta labor, pues aun cuando no es su competencia directa, sí le han dado forma al ejercicio de esta actividad. Todo este escenario ha permitido que el ejecutivo, a partir de pequeños pasos, afiance su poder, en distintos sectores, respaldado con argumentos disimiles, en la no despreciable y poderosa actividad de dirimir controversias en el país.

Apenas previsible resulta entonces el hecho que no exista interés por hacer una puesta en común, desde los distintos poderes públicos, a esta forma de administrar justicia, respondiendo a sus propias cuestiones; y que al tiempo la inserte dentro del gran tema que es la administración de justicia. De existir esa claridad, el ciudadano tendría un sistema de justicia estandarizado, con mayores garantías del derecho al acceso a la justicia, del debido proceso, del derecho a la igualdad, lo que facilitaría comprender la administración justicia como un todo y no como ruedas sueltas de lo que debiera ser un gran engranaje en un estado social y democrático de derecho.

\section{BIBLIOGRAFÍA CITADA}

Acosta Alvarado, PaOla (2010): “Administración de justicia y acceso a la justicia: el actual plan sectorial de la Rama Judicial en Colombia", en: Revista Derecho del Estado (№ 24), pp. 185-205.

Álvarez Gómez, Marco (2013): Ensayos sobre el Código General del Proceso (Bogotá, Temis).

(2018): Cuestiones y opiniones. Acercamiento Práctico al Código General del Proceso. Consejo Superior de la Judicatura. Sala Administrativa (Bogotá, Escuela Judicial Rodrigo Lara Bonilla).

Aponte SANTOS, Gustavo (2014): "Discurso de clausura del XIII Encuentro de la Jurisdicción contenciosa administrativa", en: Consejo de Estado, Memorias de la ley 1437/2011. Código de Procedimiento Administrativo y de lo Contencioso Administrativo. Antecedentes (Bogotá, Consejo de Estado), pp. 357-372.

\footnotetext{
${ }^{130}$ Ley 1753/2015, de junio 9, Artículo 108. C-087/2016, con ponencia del magistrado: Jorge Ignacio Pretelt Chaljub.

${ }^{131}$ Ley 1753/2015, de junio 9, Artículo 108.
} 
Archila Peñalosa, Emilio (2002): “iAsí no vale!”, en: Diario Ámbito Jurídico (№ 99), pp. 61-63.

Ballen Jaime, Carlos Felipe; Brito Nieto, luisa y Huertas Montero, laura Estephanía (2018): "Capitulo segundo: Complejidades del régimen actual de asignación de funciones jurisdiccionales a las autoridades administrativas", en: Rodríguez Mejía, Marcela y Bejarano Guzmán, Ramiro (Eds.), Estudio de la delegación de funciones jurisdiccionales en la rama ejecutiva: una visión global y particular (Bogotá, Universidad Externado de Colombia), pp. 5199.

Bejarano Guzmán, Ramiro (2018): “Capítulo primero. Perspectivas sobre la atribución de funciones jurisdiccionales a autoridades administrativas", en: Rodríguez Mejía, Marcela y Bejarano Guzmán, Ramiro (Eds.), Estudio de la delegación de funciones jurisdiccionales en la rama ejecutiva: una visión global y particular (Bogotá, Universidad Externado de Colombia), pp. 19-50.

BOtero BERNAL, ANDRÉs (1995): "El órgano ejecutivo como ente administrador de justicia", en: Revista de la Facultad de Derecho y Ciencias Políticas (№ 95), pp. 45-69.

CAMPOS TOVAR, Diana (2014): “¿Usurpación de funciones jurisdiccionales a cargo de las autoridades administrativas?", en: Cruz Tejada, Horacio (Coord.), El proceso civil a partir del Código General del Proceso (Bogotá, Uniandes), pp. 109-132.

CASTAÑO ARIZA, JOSÉ IGNACIO (2006): "Desplazamiento de la función jurisdiccional en autoridades administrativas con clara violación al preámbulo de la constitución de 1991", en: Revista del Instituto Colombiano de Derecho Procesal (№ 32), pp. 157-172.

Cuervo RestrePo, JoRge (2013): “Análisis y seguimiento a las políticas del sector justicia. Periodo 2011-2013", en: Revista Seguimiento y análisis de políticas públicas en Colombia (Anuario 2013), pp. 57-69.

(2015): "El componente de justicia en el Plan de Desarrollo y el Plan Sectorial de Desarrollo de la rama judicial, 2015-2018": en: Revista Seguimiento y análisis de políticas públicas en Colombia (Anuario 2015), pp. 41-55.

CRUZ TEJADA, HORACIO (2014): “El régimen de jurisdicción y competencia en el Código General del Proceso", en: Cruz Tejada, Horacio (Coord.), El proceso civil a partir del Código General del Proceso (Bogotá, Universidad de los Andes), pp. 59-83.

DuRán SMela, Diana y MALAgón Pinzón, Miguel (2016): "La fuerza del Estado: funciones estructura y elección de la Rama Ejecutiva", en: Alviar García, Helena; Lemaitre Ripoll, Julieta y Perafán Liévano, Betsy (Eds.), Constitución y democracia en movimiento (Bogotá, Universidad de los Andes), pp. 103-122.

DUSSAN HITSCHERICH, JORGE (2005): "Las funciones judiciales de las autoridades administrativas", en: Vniversitas (Vol. 54, № 109), pp. 699-731.

Fuentes Hernandez, Alfredo y Perafán Liévano, Betsy (2003): “Cambios en el sistema de justicia y sociedad civil en Colombia (1991-2002)", en: Pásara, Luis (Comp.), El papel de la sociedad civil en la reforma judicial: estudios de casos en Argentina, Chile, Colombia y Perú (Bogotá, INECI. Ediciones del Instituto), pp. 247-281.

García Barajas, Carlos (2012): "Atribuciones jurisdiccionales de la Superintendencia de Sociedades: características, críticas y dificultades" en: Revista e-Mercatoria (№ 11), pp. 1-42.

Julio Estrada, AleXei (2002): "El ejercicio de funciones judiciales por la administración pública”, en: Osuna, Nestor (Ed.), Memorias II Jornadas de derecho constitucional y administrativo (Bogotá, Universidad Externado de Colombia), pp. 275-301. 
Martínez NeiRa, NÉstor Humberto (2002): "Las que fueron funciones jurisdiccionales de las "Superes", en: Ámbito Jurídico (№110), pp. 235-238.

(2003): "Seis lustros de jurisprudencia mercantil", en: Revista Vniversitas (Vol. 59, № 105), pp.129-159.

NemogÁ Soto, Gabriel (1995): “Crisis judicial: Enfoques diferentes y elementos constantes”, en: Revista Pensamiento Jurídico. Justicia y Jueces (№ 4), pp. 107-130.

PINILLA RodRIGUeZ, Francisco (2008): "Las denominadas funciones jurisdiccionales de los órganos de la administración del estado: apreciaciones a partir de la STC de 26 de marzo de 2007" en: Revista lus et Praxis (Vol. 14, № 1), pp. 363-389.

PODER JUDICIAL (2016): Resultados del estudio de tiempos procesales (Bogotá, Consejo Superior de la Judicatura).

Ramírez torrado, María y Hernández Meza, Nelson (2018): “Análisis de las funciones administrativas y jurisdiccionales de la Superintendencia de Industria y Comercio en materia de libre competencia" en: Revista Derecho del Estado (№ 41), pp. 317-350.

República de Colombia. Asamblea Nacional Constituyente (1991a): "Informe de la sesión de la comisión cuarta del 16 de abril de 1991". Disponible en: https://bit.ly/3nOXCZW [visitado el 15 de junio de 2020].

(1991b): "Informe de la sesión plenaria del 7 de junio de 1991. Disponible en: https://bit.ly/32pUDRs [visitado el 15 de junio de 2020].

República de Colombia. Ministerio de Justicia y del Derecho (1994): “Justicia para la gente. Una Visión alternativa. Desarrollo gubernamental del plan sectorial de justicia para el periodo 19941998". Disponible en: https://bit.ly/3duP1LS [visitado el 15 de junio de 2020].

República de Colombia. Congreso de la República (1998): "Proyecto de ley 204 de 1995. Cámara de Representantes. Exposición de motivos" Disponible en: https://bit.ly/3dwOxoz [visitado el 09 de mayo de 2020].

(2004a): "Proyecto De Ley Número 112 De 2004 Senado por la cual se reforma la Ley 270/1996, Estatutaria de la Administración de Justicia y se dictan otras disposiciones" Disponible en https://bit.ly/3sUeeE0 [visitado el 08 de mayo de 2020].

(2004b): "Proyecto de ley número 157 de 2004 Senado, por medio de la cual se modifica parcialmente la Ley 270 de 1996 y se dictan otras disposiciones para propender por el acceso efectivo a la justicia, presentado por el Gobierno Nacional a través del señor Ministro del Interior y de Justicia" Disponible en https://bit.ly/3sUeeEO [visitado el 09 de mayo de 2020].

(2004c): "Proyecto de ley número 158 de 2004 Senado, por la cual se reforma la Justicia: Justicia pronta y eficaz. Disponible en https://bit.ly/3sUeeEO [visitado el 08 de mayo de 2020].

(2008): “Proyecto de ley 197/2008" Disponible en: https://bit.ly/3surgrD [visitado el 09 de mayo de 2020].

(2012): "Informe de ponencia para primer debate del proyecto de ley número 159 de 2011 Senado, 196 de 2011 Cámara, por la cual se expide el Código General del Proceso y se dictan otras disposiciones" Disponible en https://bit.ly/3sUeeEO [visitado el 08 de mayo de 2020].

República de Colombia. Consejo Superior de la Judicatura. Sala Administrativa (1996): “Acuerdo No. 237 DE 1996, Por medio del cual se fijan reglas de descongestión judicial aplicables a los Tribunales Superiores de los Distritos Judiciales de Santafé de Bogotá y de Cundinamarca". Disponible en https://bit.ly/2P3Qbor [visitado el 07 de junio de 2020]. 
(1998): "Acuerdo No 254 de 26 de febrero de 1998, Por medio de la cual se establece la metodología para elaborar el proyecto de plan sectorial de Desarrollo para la Rama Judicial 1992-2002" Disponible en: https://bit.ly/32szO2X [visitado el 07 de junio de 2020].

República de Colombia. Consejo Superior de la Judicatura (2002): "Plan Sectorial de Desarrollo para la Rama Judicial, 2003-2006, octubre de 2002" Disponible en: https://bit.ly/3goxKpK [visitado el 07 de junio de 2020].

República de Colombia. Contraloría General de la República (2014): “Justicia. Política Pública Fortalecimiento de la Justicia. Justicia formal, oral y descongestión. PND 2010-2014. Prosperidad para todos". Disponible en: https://bit.ly/3x7Fd2m [visitado el 07 de junio de 2020].

Reyes Villamizar, Francisco (1992): “Fusión de Superintendencias: ¿Para qué?”, en: Revista Derecho Público (№2), pp. 83-89.

(2002): “Revolcón”, en: Ámbito Jurídico (№ 108), pp. 203-206.

(2018): Conferencia: 10 años de la S.A.S. en Colombia, 17 de mayo de 2018 (Barranquilla, Universidad del Norte).

Rojas Ríos, Carlos Alberto (2009): “Crisis del concepto de jurisdicción en Colombia, Riesgos y desafíos", en: Memorias. XXX Congreso Colombiano de Derecho Procesal (Bogotá, Universidad Libre), pp. 755-791.

SANTELICES ARIzTía, FernANDo (2012): "Contradicción, imparcialidad e inmediación en la ley de enjuiciamiento civil española. Algunos problemas para la consolidación de estos principios en la práctica", en: Revista lus et Praxis (Vol. 18, № 1), pp. 187-248.

SUPERINTENDENCIA DE SOCIEDADES (2016): "Resolución N 500-000267 de 26 de febrero de 2016" Disponible en: https://bit.ly/32t0q8L [visitado el 07 de junio de 2020].

SUPERINTENDENCIA DE INDUSTRIA Y COMERCIO (2017): “Resolución Nº 14371 de 29 de marzo de 2017". Disponible en: https://bit.ly/3aogAEF [visitado el 07 de junio de 2020].

Torregrosa Rebolledo, Gregory De Jesús (2018): "Capítulo tercero: Aspectos procesales de la acción de protección al consumidor ante la delegatura de asuntos jurisdiccionales de la superintendencia de industria y turismo", en: Rodríguez Mejía, Marcela y Bejarano Guzmán, Ramiro (Eds.), Estudio de la delegación de funciones jurisdiccionales en la rama ejecutiva: una visión global y particular (Bogotá, Universidad Externado de Colombia), pp. 103-144.

TORRES CoRTÉs, ALEJANDRo (2015): "Política estatal en la década 2004-2014 frente a la justicia en Colombia", en: Rueda Fonseca, Maria del Socorro (Coord.), La Raíz del código general del proceso (Ley 1564 de 2012) (Bogotá, Uniandes), pp. 116-149.

TOVAR ReYes, SANDRA Lucía (2013): "Función jurisdiccional de la Superintendencia Nacional de Salud", en: Criterio jurisdicción (Vol. 13, № 1), pp. 247-266.

VARGAS VACA, HÉCtOR (2013): "Participación de los ciudadanos en gestión de conflictos", en: Revista Derecho del Estado (№ 32), pp. 297-346.

VÁsquez Alfaro, MónICA (2011): "Efectos de la ley de descongestión de despachos judiciales en la parte introductoria del proceso civil", en: Cruz Tejada, Horacio (Coord.), Impacto de la ley 1395 de 2010 frente a la Administración de Justicia (Bogotá, Universidad de los Andes), pp. 3-24.

(2014): "El Código General del Proceso Colombiano: Entre Humanización y eficientismo", en: Vásquez Alfaro, Mónica (Ed.), Temas actuales en derecho procesal y administración de justicia. Estudios críticos y comentarios al Código General del Proceso (Barranquilla, Universidad del Norte. Grupo Editorial Ibáñez), pp. 55-103. 
SALAS PASUY, BRENDA (2018): “Capítulo octavo: El derecho de autor y las funciones jurisdiccionales otorgadas a la dirección nacional de derechos de autor", en: Rodríguez Mejía, Marcela y Bejarano Guzmán, Ramiro (Eds.), Estudio de la delegación de funciones jurisdiccionales en la rama ejecutiva: una visión global y particular (Bogotá, Universidad Externado de Colombia), pp. 319-354.

\section{JURISPRUDENCIA CITADA}

Sentencias de la CoRTE Constitucional:

CoRte Constitucional, C-592/1992, de diciembre 7, Magistrado Ponente: Fabio Morón Díaz.

CoRte Constitucional, C-212/1994, de abril 28, Magistrado Ponente: José Gregorio Hernández Galindo.

Corte Constitucional, T-279/1999, de abril 29, Magistrado Ponente: Vladimiro Naranjo Mesa.

Corte Constitucional, T-494/1999, de julio 9, Magistrado Ponente: Vladimiro Naranjo Mesa.

Corte Constitucional, C-384/2000, de abril 5, Magistrado Ponente: Vladimiro Naranjo Mesa.

Corte Constitucional, C-1143 de 2000, de agosto 30, Magistrado Ponente: Carlos Gaviria Díaz.

CoRte Constitucional, C-1641/2000, de noviembre 29, Magistrado Ponente: Alejandro Martínez Caballero.

Corte Constitucional, C-649 de 2001, de junio 20, Magistrado Ponente: Eduardo Montealegre Lynnett.

CORTE Constitucional, C-415/2002, de mayo 28, Magistrado Ponente: Eduardo Montealegre Lynett.

CORTE CONSTITUCIONAL, C-1071/2002, de diciembre 3, Magistrado Ponente: Eduardo Montealegre Lynnet.

CoRte Constitucional, C-833/2006, de octubre 11, Magistrado Ponente: Jaime Araujo Rentería.

Corte Constitucional, C-1159/2008, de noviembre 26, Magistrado Ponente: Jaime Araujo Rentería.

CORTE COnStitucional, C-863/2012, de octubre 25, Magistrado Ponente: Luis Ernesto Vargas Silva.

CoRte Constitucional, C-896/2012, de octubre 31, Magistrado Ponente: Mauricio González Cuervo.

CoRte Constitucional, C-156/2013, de marzo 20, Magistrado Ponente: Luis Ernesto Vargas Silva. Corte Constitucional, C-436/2013, de julio 10, Magistrado Ponente: Mauricio González Cuervo. Corte COnstitucional, C-561/2015, de septiembre 2, Magistrada Ponente: María Victoria Calle Correa.

CoRTe Constitucional, C-087/2016, de febrero 24, Magistrado Ponente: Jorge Ignacio Pretelt Chaljub.

CoRte Constitucional, T-603/2015, de septiembre 16, Magistrada Ponente: Gloria Stella Ortiz Delgado.

\section{Sentencias Consejo de Estado:}

Consejo de ESTADO, Sala de Consulta y Servicio Civil. Abril 11 de 2002. C.P. Dra. Susana Montes. 
CONSEJO DE ESTADO, Sección Primera. Consejero ponente: Manuel Santiago Urueta Ayola. Bogotá, D. C., Auto de veintiocho (28) de noviembre del dos mil dos (2002). Radicación número: 25000 23240002001791601 (7916). Actor: Comunicación Celular S.A. Comcel S.A.

CONSEJO DE ESTADO, Sección Primera. Consejero ponente: Camilo Arciniegas Andrade. Bogotá D.C., seis (6) de agosto de dos mil cuatro (2004). Radicación número: 25000-23-24-000-20030341-01. Actor: S.O. Colombia Limitada. Demandado: Superintendencia De Industria Y Comercio. Referencia: Apelación Interlocutorio.

SENTENCIAS CORTE SUPREMA DE JUSTICIA:

CoRTE SuPRema DE Justicia, Sala De Casación Civil y Agraria. Magistrada ponente: Margarita Cabello Blanco. Bogotá D.C., diecinueve (19) de diciembre de dos mil diecisiete (2017). Radicación número: 76111-22-13-000-2017-00310-01. Actor: Luis Alberto Matta Torres y otros. Demandado: Municipio de Palmira y otros. Referencia: Impugnación fallo de tutela.

\section{NORMAS JURÍDICAS CITADAS}

DECRETO Na 2651, sobre normas transitorias para Descongestionar los Despachos Judiciales. Diario Oficial, 25 de noviembre de 1991.

LEY № 222, por la cual se modifica el Libro II del Código de Comercio, se expide un nuevo régimen de procesos concursales. Diario Oficial, 20 de diciembre de 1995.

LEY № 270, Ley Estatutaria de la Administración de Justicia. Diario Oficial, 7 de marzo de 1996.

LEY № 510, sobre el sistema financiero y asegurador, el mercado público de valores, las Superintendencias Bancaria y de Valores. Diario Oficial, 3 de agosto de 1999.

LEY № 550, por la cual se establece un régimen que promueva y facilite la reactivación empresarial y la reestructuración de los entes territoriales para asegurar la función social de las empresas y lograr el desarrollo armónico de las regiones y se dictan disposiciones para armonizar el régimen legal vigente con las normas de esta ley. Diario Oficial, 30 de diciembre de 1999.

LEY № 446, por la cual se adoptan como legislación permanente algunas normas del Decreto 2651 de 1991, se modifican algunas del Código de Procedimiento Civil, se derogan otras de la Ley 23 de 1991 y del Decreto 2279 de 1989, se modifican y expiden normas del Código Contencioso Administrativo y se dictan otras disposiciones sobre descongestión, eficiencia y acceso a la justicia. Diario oficial, 7 de julio de 1998.

LEY № 489, por la cual se dictan normas sobre la organización y funcionamiento de las entidades del orden nacional, se expiden las disposiciones, principios y reglas generales para el ejercicio de las atribuciones previstas en los numerales 15 y 16 del artículo 189 de la Constitución Política y se dictan otras disposiciones. Diario Oficial, 7 de julio de 1998.

LEY № 812, por la cual se aprueba el Plan Nacional de Desarrollo 2003-2006, hacia un Estado comunitario. Diario Oficial, 26 de junio 2003.

LEY № 1122, por la cual se hacen algunas modificaciones en el Sistema General de Seguridad Social en Salud y se dictan otras disposiciones. Diario Oficial, 9 de enero de 2007.

LEY № 1151, por la cual se expide el Plan Nacional de Desarrollo 2006-2010. Diario Oficial, 24 de julio de 2007.

DECRETO № 1018, por el cual se modifica la estructura de la Superintendencia Nacional de Salud y se dictan otras disposiciones. Diario Oficial, 30 de marzo de 2007.

LEY № 1258, por medio de la cual se crea la sociedad por acciones simplificada. Diario Oficial, 5 de diciembre de 2008. 
LEY № 1285, por medio de la cual se reforma la Ley 270 de 1996 Estatutaria de la Administración de Justicia. Diario Oficial, 22 de enero 2009.

LEY № 1429, por la cual se expide la Ley de Formalización y Generación de Empleo. Diario Oficial, 29 de diciembre de 2010.

LEY № 1480, por medio de la cual se expide el Estatuto del Consumidor y se dictan otras disposiciones. Diario Oficial, 12 de octubre 2011.

LEY № 1438, por medio de la cual se reforma el Sistema General de Seguridad Social en Salud y se dictan otras disposiciones. Diario Oficial, 19 de enero 2011.

LEY № 1450, por la cual se expide el Plan Nacional de Desarrollo, 2010-2014. Diario Oficial, 16 de junio 2011.

LEY № 1564, por medio de la cual se expide el Código General del Proceso y se dictan otras disposiciones. Diario Oficial, 12 de julio de 2012.

LEY № 1676, por la cual se promueve el acceso al crédito y se dictan normas sobre garantías mobiliarias. Diario Oficial, 20 de agosto 2013.

LEY № 1753, por la cual se expide el Plan Nacional de Desarrollo 2014-2018 “Todos por un nuevo país". Diario Oficial, 9 de junio de 2015.

DECRETO № 1817, por el cual se adiciona el Decreto 1083 de 2015, Decreto Único Reglamentario del Sector Función Pública, en lo relacionado con el nombramiento y remoción del Superintendente de Industria y Comercio, del Superintendente Financiero y del Superintendente de Sociedades. Diario Oficial, 15 de septiembre de 2015.

LEY № 1098, por la cual se expide el Código de la Infancia y la Adolescencia. Diario Oficial, 8 de noviembre 2006.

LEY № 1797, por la cual se dictan disposiciones que regulan la operación del Sistema General de Seguridad Social en Salud y se dictan otras disposiciones. Diario Oficial, 13 de julio de 2016.

LEY № 1949, por la cual se adicionan y modifican algunos artículos de las leyes 1122 de 2007 y 1438 de 2011, y se dictan otras disposiciones. Diario Oficial, 8 de enero de 2019. 